\title{
Discurso e polêmica sobre a publicação de revistas científicas na Argentina (1960)
}

\section{Pablo von Stecher}

Docente da Universidade de Buenos Aires (UBA), Argentina.

Pesquisador do Conselho Nacional de Investigações Científicas e Técnicas (Conicet).

pablovonstecher@gmail.com

Resumo Por volta de 1960, a revista argentina Ciencia e Investigación apresentou um editorial do químico Enrique Cabib que questionava as publicações científicas nacionais em função de sua qualidade limitada e escassa difusão. A proposta, rejeitada por cientistas locais de diferentes áreas, deu origem a uma controvérsia que foi publicada na revista. A fim de analisar a controvérsia, este artigo se inscreve na perspectiva discursivoargumentativa de Ruth Amossy (2011 [2008], 2016), que entende a polêmica como um confronto de vozes que tratam de um conflito de caráter público e cujos participantes não só defendem seu ponto de vista, mas procuram assegurar sua supremacia contra seus adversários. Pode-se antecipar que a polêmica está estruturada em uma troca que expõe diferentes graus de confronto - desde o "ataque cortês" à desqualificação pessoal -; e aborda um problema que desafia o pesquisador latino-americano que busca disseminar suas descobertas.

Palavras-chave: Polêmica. Ciência. Difusão. Periódicos.

Abstract. By the year 1960, the Argentine magazine Ciencia e Investigación (CEI) issued an editorial by the chemist Enrique Cabib which questioned the national scientific publications due to their inferior quality and limited dissemination. His point, condemned by local scientists of different fields, arose a controversy that was published in the magazine. With the purpose of analyzing this debate, the present article aligns itself with discursive-argumentative perspective of Ruth Amossy (2011 [2008], 2016), which conceives of polemic as a confrontation of voices that deal with a conflict of public character and whose participants not only defend their point of view but try to ensure their supremacy over that of their opponents. It can be anticipated that the controversy is structured as an exchange that exposes different degrees of confrontation - from the "polite attack" to personal disqualification -; and approaches a problem that implicates the Latin American researcher that tries to disseminate his findings.

Keywords: Controversy. Science. Dissemination. Journals. 
Introdução

A revista Ciencia e Investigación (CEI), patrocinada pela Associação Argentina para o Progresso das Ciência (AAPC), foi publicada pela primeira vez no país em 1945. A AAPC foi fundada em 1933 por Bernardo Houssay (18871971), célebre médico argentino, diretor do Instituto e do Departamento de Fisiologia da Universidade de Buenos Aires desde 1919 e Prêmio Nobel de Fisiologia em 1947. O objetivo da associação consistia na expansão científica nacional por meio da vinculação entre pesquisadores, a coordenação de bolsas, a aquisição de recursos e a cooperação com o desenvolvimento industrial local'.

Durante seus primeiros quinze anos, a CEI teve como diretor Eduardo Braun Menéndez (1903-1959), também fisiologista e membro da AAPC. A revista possuía tiragem mensal e seus conteúdos concentravam-se na área de ciências exatas e naturais. Suas seções permanentes, além da "Nota Editorial", eram: "Artigos Originais", "Organização do Ensino e Pesquisa”, "O mundo científico", "Os Prêmios Nobel” e "Notícias da AAPC". Josefina Yanguas (2015, p. 94), que era secretária de Houssay, fez um relato do importante papel didático que a revista teve ao explicar, por exemplo, o que era um instituto de pesquisa ou em que consistia o trabalho do cientista, temas sobre os quais prevalecia uma ignorância generalizada até então no país.

A década inaugural da CEI (1945-1955) coincidiu com as primeiras presidências de Juan Domingo Perón, cujas políticas voltaram-se ao desenvolvimento das áreas técnicas, com o objetivo de aprofundar o processo de industrialização, guiado por interesses do setor militar (HURTADO e BUSALA, 2006). Durante estes anos, muitas universidades argentinas sofreram intervenções e muitos professores, entre eles Houssay e Braun Menéndez, foram demitidos de seus cargos. Com a derrubada de Perón, em 1955, como consequência da Revolução Libertadora, universidades foram ocupadas por grupos estudantis opostos ao peronismo, cátedras e corpo docente foram reintegrados (BUCHBINDER, 2005, p. 148-151). Em fevereiro de 1958, Houssay, Braun Menendez e pesquisadores de diferentes áreas criaria o Conselho Nacional de Investigações Científicas e Técnicas (CONICET), uma

\footnotetext{
${ }^{1}$ A AAPC seguiu o modelo associativo difundido pelo mundo desde o século XIX. Entre outras Associações para o Progresso das Ciências, a Associação Britânica foi fundada em 1831; a Associação Estadunidense, em 1848, e a Associação Espanhola, em 1908. Em 1948, foram criadas a Associação Brasileira e a Associação Uruguaia.
} 
instituição que atualmente coordena e finanças grande parte das atividades científicas no país.

Em agosto de 1960, a CEI publicou um editorial do bioquímico Enrique Cabib intitulado "Revistas científicas devem ser publicadas na Argentina?" pergunta a que o autor responde negativamente. Diferentes considerações que oscilaram entre a surpresa, a crítica e a frustração contra o posicionamento de Cabib foram publicadas na revista e deram origem a uma polêmica que será objeto de análise neste artigo. Em seguida, serão especificados os referenciais teóricos que norteiam este estudo, bem como as fontes e materiais de análise. Uma vez investigados os vários argumentos que confluem no debate, extraem-se considerações tanto sobre os mecanismos de confrontação que sustentam a polêmica, com acerca dos interesses concernentes à divulgação científica que gera o tópico em questão.

\section{Referencial teórico e corpus de análise}

O artigo enquadra-se na perspectiva desenvolvida por Ruth Amossy (2011 [2008]) que inscreve o estudo da argumentação no seio da Análise do Discurso (especificamente em abordagens francesas contemporâneas) o que implica, em termos gerais, atribuir à análise argumentativa sua dimensão institucional e social em vez de concebê-la no espaço abstrato da lógica pura (AMOSSY, 2008, p. 132-133) ${ }^{2}$. A partir dessas diretrizes, Amossy definirá a argumentação como um continuum discursivo que manifesta diferentes graus de confronto e em cujos polos discursos encontram-se os discursos que silenciam o adversário e "apagam" o caráter de confronto, por um lado; e aqueles que exacerbam o conflito e expõem o choque ostensivo de posições, por outro. Nesse sentido, explica Amossy (2016, p. 25-26), a polêmica é necessariamente inscrita na argumentação. No entanto, como Amossy, outros referenciais do campo como Christian Plantin (2016, p. 68) e Marc Angenot (2016, p. 39-40) observaram como os antigos tratados retóricos assim como os estudos argumentativos de meados do século XX, Perelman e OlbrechtsTyteca, Toulmin, e, inclusive, as contribuições posteriores da Lógica Natural de J. B. Grize, distanciaram-se da análise da polêmica e dos desacordos que

\footnotetext{
2 De fato, Amossy (2011 [2008], p.133) recupera a voz de Dominique Maingueneau (2002) apontando que sua abordagem adota a vocação da Análise do Discurso ao apreender o "discurso como uma complexidade de um texto e de um lugar social". A partir disso, ele propõe investigar a argumentação em uma situação comunicativa concreta e articulada em linguagem natural, bem como atender à construção do dispositivo enunciativo e à problemática da materialidade e profundidade da linguagem.
} 
persistem aos debates. Tais operações têm-se centrado principalmente no estudo de técnicas discursivas que permitem melhorar a adesão dos sujeitos às teses que lhes são apresentadas, buscar acordos ou refletir sobre a idealizada arte de persuasão mediada pelo discurso ou por meio de debates bem regulamentados. Esse interesse pelo consenso opõe-se à paixão pelo dissenso própria de toda relação polêmica, destaca Plantin (2016, p. 69), o qual também afirma que após a reflexão discursiva e linguística é mais enriquecedora a abordagem das controvérsias que a análise dos acordos.

O discurso polêmico consiste no confronto de, ao menos, duas opiniões que tratam não apenas de expor e defender o próprio ponto de vista, mas também de garantir sua supremacia sobre as outras posições em debate (AMOSSY, 2016, p. 26). O significado da polêmica como "guerra verbal" implica a existência de um "alvo" ou objeto de ataque pode muito bem ser um ponto de vista ou a pessoa que o encarna, tal como foi observado por Catherine Kerbrat-Orecchioni (1980), mas deve-se esclarecer que nem todos os discursos polêmicos manifestam explicitamente a desqualificação em relação ao outro ou a violência discursiva. Em consonância com as referências anteriormente mencionadas, Ana Montero (2016, p. 15) confirma que, para a existência de uma polêmica, é necessário que a questão em jogo seja de caráter público e de interesse compartilhado, pelo menos para uma comunidade mais ou menos vasta.

Uma vez identificados, detectados e ordenados os documentos que deram origem a presente polêmica, e de acordo com as orientações descritas, procedeu-se ao estudo das formas enunciativa e das estratégias lógicas e emocionais na conformação de argumentos, refutações, contra-argumentos e enunciados desqualificadores do adversário. O corpus de análise consiste, então, em uma série de artigos publicados sob o mesmo título - "Revistas científicas devem ser publicadas na Argentina?" - em diferentes gêneros discursivos (editoriais, colunas de debate e de opinião) da CEl. Eles são de autoria do bioquímico Enrique Cabib (1960, 1961a, 1961b), do doutor em botânica Teodoro Meyer (1961), do químico e bromatologista Peter Cattáneo (1961), do engenheiro agrônomo Arturo Burkart (1961), e dos pesquisadores em química Carlos Cardini (1961) e Máximo Barón (1961). A polêmica é concluída, embora não encerrada, com reflexo do corpo editorial da CEI (1961).

Antecipo que a estratégia de locutor questionado (CABIB), cujos enunciados são conduzidos pelo eixo discursivo da mudança, consistirá na adoção de respostas que flutuam entre a objeção categórica e a repressão 
$\mathrm{EI} \square \mathrm{dA}$

Revista Eletrônica de Estudos Integrados em Discurso e Argumentação, Ilhéus, n. 17, jul./dez. 2018.

comedida ou condescendente, de acordo com os diferentes graus de questionamento e/ou queixa previamente recebidos. Antecipo também que esta polêmica expõe uma série de preocupações que atualmente interpelam o pesquisador latino-americano - ou distantes dos centros hegemônicos de produção científica - que tenta disseminar suas descobertas e contribuições na comunidade científica.

\section{Agosto de 1960. O motivo do escândalo}

Revistas científicas não devem ser publicadas na Argentina, sintetiza Cabib no editorial original que deu origem à polêmica. A defesa de seu ponto de vista tem início com as duas únicas afirmações com as quais os demais envolvidos concordarão: a) a pesquisa científica argentina vem de um longo período de estagnação; b) no entanto, desde os últimos anos, tem-se tentado impulsionar vigorosamente a pesquisa local. Esclarecemos que, embora alguns projetos científicos realizados pelo peronismo tivessem falhado ${ }^{3}$, a ciência e a tecnologia argentina contaram com certas iniciativas e realizações durante esses anos: as criações da Comissão Nacional de Energia Atômica (1950), do primeiro Conselho Nacional Investigações (1951) e da Universidade Obrera Nacional (1953), posteriormente denominada Universidade Nacional Tecnológica (BUCHBINDER, 2005, p. 155-159). A partir das páginas da CEI, o período foi caracterizado pela falta de autonomia na atividade científica, a primazia de critérios utilitaristas e das tentativas de subordinar a ciência ao Estado (HURTADO e BUSALA, 2006, p. 30). A este respeito, observou-se que CEI tentou atingir a opinião pública para disseminar sua própria representação do campo científico e sua perspectiva cética sobre a precariedade da ciência local e suas propostas para superar os conflitos detectados (HURTADO E BUSALA de 2001, p. 40).

A função das publicações científicas, explica Cabib, é divulgar os resultados obtidos por uma pessoa ou grupo para que possam ser tomados como base de outros estudos. Enquanto a ciência é uma atividade internacional, é essencial que os periódicos publicados por associações profissionais e científicas tenham um alto nível de divulgação. O problema é que as publicações locais são desconhecidas no meio estrangeiro ou seus

\footnotetext{
${ }^{3}$ É um caso famoso o malfadado projeto de energia nuclear idealizado pelo físico austríaco Ronald Richter na ilha de Huemul (Patagônia) e coordenado pelo peronismo na década de 1950.
} 
$\mathrm{E} \mid \mathrm{D} \overline{\mathrm{A}}$

Revista Eletrônica de Estudos Integrados em Discurso e Argumentação, llhéus, n. 17, jul./dez. 2018

resumos são divulgados apenas em órgãos como Chemical Abstracts ${ }^{4}$ - um fato que Cabib afirma poder corroborar a partir de suas estadias no exterior. A razão para a difusão limitada reside na falta de originalidade de seus artigos e nas abundantes repetições de achados alcançados em outros espaços, dados aos quais o pesquisador apenas acrescenta algumas poucas observações.

Embora Cabib admita a existência de um trabalho de qualidade local, destaca que estes são principalmente publicados em revistas de circulação internacional, e sua quantidade reduzida é insuficiente para compor uma publicação alta patente em quaisquer ramos científicos. Consequentemente, as revistas locais são pouco úteis, pois não resistem a uma análise rigorosa, envolvendo um gasto de tempo e de dinheiro que poderia ser destinado à pesquisa e tendem a ser manipuladas pelos autores a fim de acumular publicações para a ganhar concursos, gerar influências ou deslumbrar o público inexperiente. Que solução Cabib propõe em resposta a esta situação? Produzir uma única revista que, em vez de apresentar artigos originais, reimprima uma seleção de trabalhos já publicados pelos argentinos em periódicos internacionais. Assim seria obtida uma compilação de alta qualidade, capaz de disseminar a pesquisa local efetiva e de qualidade, promover o diálogo entre pesquisadores, evitar leituras excessivamente especializadas, orientar os jovens interessados em pesquisa e eliminar a criação de registros falsos. Também seria possível para o Conicet, as universidades e os órgãos competentes terem uma ideia completa do desenvolvimento argentino. Sem muitas esperanças de que as academias ou sociedades científicas renunciassem às suas publicações, Cabib encerra o artigo indicando que o Conicet seria o organismo ideal para levar adiante este projeto.

\section{Março de 1961. Acusações contra Cabib}

As repercussões pelo texto de Cabib foram inesperadas. Teodoro Meyer, botânico do Instituto Miguel Lillo (Tucumán), caracteriza-o como uma abordagem revolucionária e de desacredito em relação à ciência argentina no exterior. Ele refuta o primeiro argumento com base na enumeração de revistas locais com conteúdos valiosos e originais que são consultados na

\footnotetext{
${ }^{4}$ Trata-se da revista americana, criada em 1907 e dedicada à divulgação de resumos e sinopses de artigos na área de química.
} 
Europa e nos EUA 5 . Justifica a apreciação pelo valor do que é útil, dadas as contribuições arquivísticas e descritivas geradas, especialmente as revistas dedicadas à zoologia, à botânica e à agronomia nacional. Enquanto Meyer desqualifica a proposta de Cabib, ele o faz por meio de procedimentos que mitigam o ataque, como concessões e os modalizadores ${ }^{6}$. Por caso, ele afirma: "Certamente o Sr. Cabib terá se referido a uma ciência determinada [...] mas há outros que caminham para vanguarda"; "Provavelmente há pessoas no país, como diz o Sr. Cabib, que publicam trabalhos medíocres[...], mas estes são a minoria" (MEYER, 1961, p. 50). Assim, embora se desacreditem os argumentos sobre as publicações serem utilizadas como forma de promoção pessoal e sobre a limitada atividade científica local, o grau enfrentamento é reduzido mediante a aceitação de pontos de partida admissíveis nos raciocínios, instância que se reforça por meio dos advérbios de atitude que introduzem os enunciados e que atuam como modalizadores ao situarem os julgamentos em uma faixa de verdade ou de alta probabilidade.

Para corroborar a qualidade das revistas locais, Meyer recupera um lugar da quantidade ${ }^{7}$ ao explicar o grande número de assinaturas estrangeiras recebidas por instituições argentinas que contam com órgãos difusão. Para Meyer, a proposta de revista única não se sustenta, uma vez que limita as oportunidades locais de publicação, assim como força os candidatos a se submeterem a processos de avaliação no exterior que levam muito tempo e prejudicam a originalidade dos trabalhos.

A intervenção de Cattáneo - membro da Cátedra de Bromatologia e Análise Industrial (Faculdade de Ciências Exatas, da Universidade de Buenos Aires) - problematiza questões até então dadas como certas. Por um lado, pergunta o que se entende por uma "produção original". Se deve ser definida pelo uso de técnicas originais, então, a pouquíssimas elaborações poder-se-ia atribuir esse caráter, não apenas na Argentina, mas no mundo científico. Por outro, introduz um fator-chave, embora infelizmente silenciado durante o

\footnotetext{
${ }^{5}$ Trata-se de: Physis, Darwiniana, Revista Argentina de Agronomía, Acta Zoológica Lilloana, Revista de Investigaciones Agronómicas, Revista del Museo de La Plata, Boletín de la Sociedad Argentina de Botánica, Cuadernos de Minería y Geología de la U.N.T., entre outras. (MEYER, 1961, p. 49).

${ }^{6}$ Kerbrat-Orecchioni (2016, p. 99-101) recupera aspectos do modelo de cortesia de Brown y Levinson para dar conta dos procedimentos que confluem no fenômeno denominado "desqualificação cortês do adversário" (ou seja, a desqualificação que adota certas aparências de polidez). Para suavizar o ato de ameaçar a imagem do interlocutor, o locutor pode "polir" suas afirmações por meio de diferentes procedimentos: eufemismos, lítotes, concessões, modalizadores, tropos, entre outros.

${ }^{7}$ A esse respeito, ver Perelman e Olbrechts-Tyteca (1989, p. 148-151). N.T. Na edição brasileira (1999 [1958], pp. 100-105).
} 
resto da polêmica: as dificuldades do espanhol como língua da ciência. Sobre esta questão, Bernardo Houssay havia se manifestado por meio de gestos significativos, tais como a reivindicação do médico espanhol Santiago Ramón y Cajal (Prémio Nobel em 1906) e sua demonstração da compatibilidade dessa linguagem não apenas com criações artísticas, mas também científicas (HOUSSAY, 1989 [1934], p 431); seu convite a pesquisadores dos Estados Unidos para conhecer as outras línguas americanas (espanhol e português) e falar na língua do país anfitrião dos futuros congressos de que participassem (HOUSSAY, 1989 [1936A], p. 574); a denúncia da tendência dos grandes centros de pesquisa de considerar apenas as contribuições feitas no país ou na língua nacional (HOUSSAY, 1989 [1959], p. 219). No entanto, coexistiam com essas abordagens reivindicatórias perspectivas como as de Enrique Gaviola (1948, p. 118), então presidente da Associação Física Argentina, o qual defendia que o espanhol era uma língua pouco atualizada, com regras sintáticas anacrônicas, desprovido de neologismos e incapaz de explicar novos avanços científicos.

Mais próximo de Gaviola que de Houssay, Cattáneo destacará a trajetória limitada e a experiência do espanhol (entre outras línguas) em termos de produção científica. Em vez de enfatizar seu desenvolvimento e empoderamento na prática da disseminação escrita, sugere a redação de artigos em inglês ou alemão em periódicos locais. Na verdade, deve-se notar que, pelo menos desde 1970 e uma vez admitido o inglês como uma língua internacional da ciência ${ }^{8}$, tem aumentado o número de autores não falantes do idioma que publicam seus trabalhos nesta língua no contexto de revistas locais, assim como se aprofundou a decisão de revistas nacionais por serem publicadas inteiramente em inglês (NAVARRO, 2001, p 37; HAMEL, 2013, p. 330).

O auspicioso momento atual por que passa a ciência local é o argumento que Cattáneo propõe para refutar a proposta da revista única. Sobre isso, sentencia: "Ninguém contesta que na Argentina houve um sério atraso em relação à produção científica [...]. No entanto, algo vem acontecendo nos últimos anos. O Estado, os esforços privados e os de muitas organizações estrangeiras e internacionais importantes ajudam a criar um ambiente

\footnotetext{
${ }^{8}$ Como apontam Navarro (2001, p.36-37) e Hamel (2013, p.127), entre outros, o predomínio da língua inglesa na atividade científica não deriva de sua superioridade linguística sobre outras línguas, mas de sua supremacia política, econômica, técnica e cultural desde o final da Segunda Guerra Mundial. Como acontece em outros tipos discursivos, essa formulação de oposição tem sido atualizada em diferentes instâncias e por diferentes vozes do discurso científico argentino Montes de Oca (1852), Ramos Mejía (1893), Houssay (1958) - que se propuseram a (re-)fundar a ciência nacional após um período de estagnação ou conflito.
} 
propício ao seu desenvolvimento" (CATTÁNEO, 1961, p. 51). Do nosso ponto de vista, esse argumento é constituído como um tópico recorrente e representativo do discurso científico argentino. Ele é formado a partir do confronto entre dois momentos com base no par antitético "passado / presente" - detectável no exemplo por meio da utilização do pretérito perfeito composto frente ao presente progressivo e da referência a "nos últimos anos" -, a ruptura ou o distanciamento com aquele passado de atraso por meio do conectivo adversativo e a consequente projeção do momento atual como temporalidade favorável ao desenvolvimento científico ${ }^{9}$. A conclusão do argumento é realizada com a apresentação de duas perguntas retóricas (uma vez superar a estagnação mencionada) questionam: “É então razoável propor a abolição de nossas revistas científicas? Não seria mais prudente garantir sua melhoria, para assegurar sua periodicidade? Convido formalmente o autor do editorial a colaborar nessa nobre tarefa" (CATTÁNEO, 1961, p. 51).

A desqualificação da proposta de Cabib, objeto de ataque de Cattáneo, torna-se levemente moderada aqui não apenas pela suposta "não imposição de julgamentos" que é decorrente do uso de perguntas retóricas, mas também pelo caráter impessoal com que as perguntas são formuladas. No entanto, e apesar da camaradagem inscrita no convite a Cabib para formar um esforço construtivo e coletivo que permita uma melhor documentação, são explicitadas as críticas subjacentes à sua abordagem, em termos de "imprudência" e "irracionalidade". Um segundo movimento de confronto, mais falho que o anterior, consiste em atribuir a Cabib a afirmação de que "todo texto publicado no exterior constitua por si mesmo uma contribuição e um registro real", declaração que, de fato, não foi realizada pelo químico, mas que permite a Cattáneo (1961, p. 52) propor que os materiais valiosos são difundidos e circulam, independentemente dos meios em que tenham sido publicados. Finalmente, ele propõe que seja o Conicet que seleciona cuidadosamente as revistas que merecem apoio financeiro.

"Vejo-me na obrigação moral de me dirigir a você para expressar-lhe a penosa impressão deixada em meu ânimo", assim introduz o engenheiro Burkart (1961, p. 52), em uma coluna que se afasta da lógica do raciocínio e das

\footnotetext{
${ }^{9}$ Como acontece em outros tipos discursivos, essa formulação de oposição tem sido atualizada em diferentes instâncias e por diferentes vozes do discurso científico argentino - Montes de Oca (1852), Ramos Mejía (1893), Houssay (1958) - que se propuseram a (re-)fundar a ciência nacional após um período de estagnação ou conflito.
} 
$\mathrm{EI} D \bar{\alpha} \mathrm{A}$

Revista Eletrônica de Estudos Integrados em Discurso e Argumentação, Ilhéus, n. 17, jul./dez. 2018.

provas. Generaliza, logo de início, a ofensa percebida ao destacar que as palavras de Cabib representam uma afronta não apenas para os resultados de nossos pesquisadores, mas para toda a comunidade científico-editorial. Sem rodeios, afirma: "Está equivocado, Sr. Cabib" e atribuiu suas opiniões "aos efeitos de um momento de depressão ou uma experiência pessoal infeliz" (BURKART, 1961, p. 52). Desse modo, transfere o conflito para o terreno de descrédito explícito e pessoal diante da depreciação da condição mentalemotiva do locutor, um recurso que pode chamar a atenção dadas as formalidades que envolvem o circuito e o campo da comunicação. Para Burkart, a proposta Cabib, que não foi sequer remotamente vista em qualquer outro lugar no mundo, implicaria diretamente um "suicídio científico nacional". A natureza persuasiva que suporia essa metáfora, contundente e definitiva, não compensa a falta de fundamentos. Burkart (1961, p. 52) orgulha-se de possuir "documentos e registros que permitem refutar todas as declarações negativas do Sr. Cabib [...], mas, em respeito à brevidade sentencia- não entrarei em detalhes". O que é menos eficaz para uma argumentação que afirmam ter o ônus da prova, mas não o expor por razões de espaço?

\section{Março de 1961 (2). Resposta e contra-ataque}

Em função do interesse causado pela polêmica, Cabib é convocado pela CEI para responder aos três retornos recebidos. O químico diferencia o caráter das réplicas e decide responder, em princípio Cattáneo e Meyer. É interessante observar a maneira pela qual seu discurso reproduz os mesmos recursos mitigadores desqualificadores articulados por Meyer (concessões e modalizadores). Sobre as propostas do último, aceita a existência necessária de revistas com fins de registro e classificação de dados em ciências descritivas como a botânica ou a zoologia, mas esclarece que se trata de um critério que não alcança as áreas teórico-experimentais (física, química, fisiologia). Opõe-se, da mesma forma, à crença de que artigos enviados para o exterior implicam maiores atrasos ou dificuldades. Acerca dos argumentos de Cattáneo, assume a dificuldade de definir “o original”, mas esclarece que, sob seu ponto de vista, tal concepção não implica necessariamente a utilização de "técnicas originais". Enfatiza a boa intenção de tentar aumentar os requisitos nos critérios de aceitação de artigos locais, mas indica que o problema está, precisamente, no número muito pequeno de trabalhos com um "nível 
$\mathrm{EI} D \overline{\alpha A}$

Revista Eletrônica de Estudos Integrados em Discurso e Argumentação, Ilhéus, n. 17, jul./dez. 2018

aceitável". A formulação desses contra-argumentos é articulada por diferentes expressões verbais ("eu penso", "acredito") ${ }^{10}$ que conferem aos enunciados uma nuance de possibilidade e não de certeza absoluta. Ainda mais, para refutar a afirmação que Cattáneo Ihe atribui, Cabib (1961a, p. 53, grifos do autor) não recorre à negação absoluta, mas sentencia: "não pude encontrar no meu artigo a declaração atribuída a mim pelo Dr. Cattáneo, de que tudo o que é publicado em outro lugar constitui um registro real e não falso". Pelo contrário, corrobora Cabib, a sugestão de formar um comitê que selecione os trabalhos a serem republicados confirma que a afirmação não tem lugar válido na argumentação.

Enquanto Burkart foi "escolhido para expor apreciações de conteúdo essencialmente emocional", Cabib (1961a, p. 53) afirma "pouco posso contestá-lo", mas deve "todavia adverti-lo" de que, longe de ser a única, sua posição tem contado com notáveis coincidências por parte de diferentes colegas. Dada a lógica do agravo e da ameaça à sua imagem pessoal, o contraataque de Cabib visa a desacreditar e silenciar um discurso que merece respostas e a delinear o aviso final. Entre outras vozes que Cabib declara semelhantes à sua posição, encontra-se a do químico Carlos Cardini, colega no Instituto de Pesquisa Bioquímica da Fundação Campomar. O enriquecimento da incorporação de sua palavra para o desenvolvimento da própria polêmica mas também para seu estudo - é evitar o desequilíbrio de vozes que representam as diferentes posições. Enquanto Cardini prontamente assume o risco envolvido no caráter "unilateral" que teriam as conclusões de dois profissionais da mesma área, rapidamente ele garante que as razões de Cabib e as suas próprias não são excepcionais, mas as mais comuns na área.

Cardini enfrenta as duas questões centrais da polêmica. A primeira, por meio de um raciocínio cujas premissas são: a) a especialização científica tem feito proliferar as publicações atuais que estão em constante crescimento, b) uma biblioteca não pode contê-las em sua totalidade e o pesquisador, por sua vez, tem a dificuldade dupla de lê-las e conseguir que "seus trabalhos sejam lidos por outros cientistas". A conclusão lógica é que o pesquisador apela para publicar em revistas de máxima difusão. O corolário desse fenômeno é duplo: enquanto essas publicações monopolizam o melhor da produção mundial, as

\footnotetext{
${ }^{10}$ Em suma, ele aponta: “Me parece difícil melhorar muito o nível das revistas científicas nacionais", "Acredito que é quase impossível decidir quando uma obra é original ou não", "Parece lógico deixar a taxonomia fora da discussão", entre outros (CABIB, 1961a, p. 53).
} 
locais ou periféricas "publicadas em várias línguas", não contam com grandes contribuições e são muito menos lidas (CARDINI, 1961, p. 53).

A segunda questão, já levantada por Cabib, aponta para a impossibilidade de apoiar uma revista local especializada e de leitura forçada no exterior por causa da qualidade insuficiente de nossa produção. $O$ argumento com que Cardini busca corroborar sua hipótese reside em sua experiência como um membro de comitês científicos e, assim, na convicção de que um grande número de trabalhos publicados na Argentina não tinha sido aceito no exterior. Então, por meio da introdução de um raciocínio contrafatual, Cardini (1961, p. 54) imagina que, se os candidatos tivessem sido encorajados a produzir seus trabalhos para uma revista estrangeira de nível, provavelmente "teriam feito algo mais produtivo"11. Em outras palavras, o órgão de difusão selecionado influenciaria no esforço dos autores para garantir a qualidade de seu artigo, o que criaria um círculo que se retroalimenta entre as representações que o pesquisador tem sobre o valor de revistas locais e aquelas sobre o valor de suas próprias produções.

A partir do que foi mencionado até aqui, pode ser confirmado que Cabib e Cardini estão dispostos a fazer trabalho profundo e desconfortável de autocrítica para o desenvolvimento científico argentino e difusão, e não temem expor, de modo forma frio e contundente, os obstáculos e as causas. Da perspectiva oposta, e apesar das concessões ou pontos de coincidência, os argumentos e dados oferecidos estão entrelaçados com sentimentos de indignação e com lugares emocionais ligados ao patriotismo e ao orgulho da ciência nacional.

\section{Outubro de 1961. A continuidade do dissenso}

Sete meses após a referida troca de correspondências, a polêmica terá um novo e último capítulo nas páginas da CEl. Quem abre o jogo agora é Máximo Barón, membro do Laboratório de Pesquisas Químicas Atanor. Ele introduz o diálogo com Cabib por meio de movimentos concessivos que, nesse caso, são articulados a diferentes tipos de elogios. Iniciar uma discussão dessa envergadura, tal como fez Cabib, supõe um esforço "louvável" e emitir uma opinião independente e exposta à crítica pública é "algo digno de mérito”,

\footnotetext{
${ }^{11}$ Angenot (2016, p. 46) tem questionado o uso do raciocínio contrafatual nos argumentos devido à impossibilidade de extrair conclusões práticas ou correções fundamentadas a partir de uma proposição contrária aos fatos.
} 
ainda mais, trata-se de uma "atitude rara em nosso meio no qual a prevalecem censuras particulares” (BARÓN, 1961, p. 443). Barón aceita as deficiências de revistas locais (excesso, frequência irregular, conteúdo pobres, atraso) e o fato de que não cumprem sua missão básica: informar o que acontece (e que deve ser feito) nos centros científicos argentinos. Entretanto, similar a intervenções anteriores, o conectivo adversativo prontamente é utilizado para introduzir o distanciamento: "No entanto, não acredito que a maneira de corrigir esta situação seja eliminar as revistas", confirma Baron (1961, p. 443). Seu alvo de ataque é também a sugestão da revista única e, por meio de uma dissociação do par de "aparência / realidade"12, defende que "a aparente utilidade desta solução" não considera alguns fatos que, embora talvez sejam pouco evidentes, não por essa razão, "deixam de ser menos reais".

Tais fatos implicam: 1) uma prova forjada por meio de um dado verificável: efetivamente há conhecimento das revistas argentinas no exterior. Como evidenciado pelos Chemical Abstracts (mesma fonte utilizada por (abib), os Anais da Associação Química Argentina chegam a 20 bibliotecas dos EUA e os Anais da Sociedade Científica chegam a 40, números não menores que as assinaturas de revistas europeias (Anales de la Real Sociedad de Física y Química de Madri ou da Gazzeta Chimica Italiana). 2) Um raciocínio: por razões econômicas, os editores tendem a preferir publicar revistas de maior circulação que os periódicos acadêmicos (esportivas, por exemplo). Ao contar com menos recursos, os editores dedicados à pesquisa demoram mais para publicar. De qualquer forma, defende Barón, esses tempos são semelhantes nos âmbitos nacional e internacional - entre seis e dez meses. No entanto, a reedição da única revista levará a um atraso maior, uma dificuldade que será exacerbada pela falta de pressa que os autores terão de reimprimir seus textos. 3) A antecipação de uma consequência: a revista única aprofundará mais o isolamento que existe atualmente na produção científica argentina. Ao contrário de Cardini e Cabib, Barón argumenta que a intenção de publicar no exterior é parte do desejo dos cientistas argentinos de não expor suas pesquisas a considerações e críticas - mesmo construtivas - de colegas locais. Acrescenta-se a isso que, por não haver um diálogo fluido entre nossos

\footnotetext{
${ }^{12}$ Como em outros pares filosóficos, no par aparência/realidade, explicam Perelman e OlbrechtsTyteca (1989, pp. 633-635, 640), o segundo termo fornece uma regra que desqualifica os aspectos errôneos e duvidosos do primeiro termo e, a partir daí, estabelece as hierarquias e os critérios que determinam uma visão do mundo. N.T. Na edição brasileira (1999 [1958]), as referências encontram-se às pp. 472-502
} 


\section{$\mathrm{El} \square \mathrm{dA}$}

pesquisadores e os estrangeiros, não há interesse do exterior em publicar no país, o que resultaria no empobrecimento de nossos periódicos.

Barón acredita haver uma contradição no raciocínio de Cabib, o qual havia argumentado que os trabalhos de qualidade são publicados no exterior e, ao mesmo tempo, que a produção de textos em centros argentinos é insuficiente para uma revista de alto nível. Baron (1961, p. 444), então refuta que se este último fosse verdade, não seriam "tão numerosos os trabalhos aceitos pelas principais revistas de alto nível”. A falha na confrontação ao raciocínio de Cabib é que ele não havia indicado que esse número era alto, então a objeção a ele não teria fundamento.

Se o principal problema para Barón (1961, p. 445) é a "sensação de isolamento que durante tanto tempo afetou a ciência argentina", então sua solução reside em estimular as revistas locais que, efetivamente, efetivamente alcançado certo nível e não temam rejeitar trabalhos insuficientes. Para que esse número de publicações sérias alcance editores relevantes, propõe que sejam concedidos subsídios temporários (até que a divulgação internacional as torne dignas de crédito por sua qualidade). Mas ele sugere que essas revistas não se atomizem - outro defeito recorrente - mas que aceitem artigos (desde que sejam nível, é claro) para qualquer um dos ramos envolvidos na disciplina. Dado que o Conicet possui membros qualificados, deve ser o órgão indicado para selecionar os periódicos a serem subsidiados e financiar o projeto.

Pela última vez, CEI dá voz a Cabib, que reconhece e, reciprocamente, elogia também o seu interlocutor, em função da "virtude" que envolve suas "observações fundamentadas" e seus "dados concretos". A objeção, entretanto, é que "eles partem dos conceitos equivocados" (CABIB, 1961b, p. 445). De modo sintético, refuta o argumento quantitativo sobre a subscrição de revistas locais em bibliotecas internacionais. Para Cabib, um número de referência é, por exemplo, as 213 bibliotecas nas quais o Journal of Biological Chemistry é distribuído, uma publicação que efetivamente promove a "real circulação internacional”. Desconstrói a falsa contradição que Baron lhe atribui. E, finalmente, questiona o apoio que o Conicet deve dar aos periódicos científicos, pelo menos até que não haja razões convincentes para corroborar a importante missão que essas publicações cumprem.

Após a conclusão deste capítulo final da polêmica, os editores da CEI, que até aquele momento haviam se limitado a divulgar as posições 


\section{$\mathrm{EI} D \bar{\alpha} \mathrm{A}$}

Revista Eletrônica de Estudos Integrados em Discurso e Argumentação, Ilhéus, n. 17, jul./dez. 2018.

antagônicas, formularam uma reflexão final em que confirmam que - para além da polêmica - as revistas têm seguido seus caminhos tradicionais. Além disso, eles também introduzem um ponto pouco discutido durante o intercâmbio: o papel da imprensa científica frente aos problemas de nossa sociedade atual. Em sua opinião, os institutos científicos argentinos e seus órgãos de difusão estão afastados dos conflitos que impedem o progresso do país. Sentenciam, então, que a ciência argentina deveria atingir altos patamares conceituais, mas "baseada nas realidades que nos apresenta o solo nacional" (CEI, 1961, p. 538).

Entre outras consequências atuais do interesse em publicar em revistas internacionais, observou-se a dificuldade de acesso aos conhecimentos ou resultados de pesquisa sobre questões locais por aqueles que deveriam ser seus destinatários naturais (NAVARRO, 2001) ${ }^{13}$. Interessa acrescentar que a busca de legitimidade e prestígio envolvida na publicação de resultados a partir dos grandes centros de pesquisa mundial impossibilita observar o quão enriquecedor, em termos de pensamentos e reflexões, pode ser o fato de publicação no país ou na região um trabalho de interesse comum Se pensamos nos diálogos, nas controvérsias e, inclusive, nas polêmicas como motores de conhecimentos e ideias, (para além do desacordo final), perguntam-nos, então, que debates e polêmicas podem ser alcançados em problemas localizados em áreas mais distantes e afastadas das discussões propostas?

Em relação à controvérsia suscitada, conclui a CEI (1961, p. 538), ainda é necessário abrir novos caminhos e um amplo debate nas reuniões e na imprensa, "a questão das revistas científicas nacionais deve ser repensada de novo", porque - como é típico de toda polêmica - "ficou sem solução".

\section{Considerações finais}

Dois anos após a fundação do Conicet (1958), os textos que compõem esta polêmica explicitam uma série de dificuldades inerentes à divulgação científica argentina. Enquanto Bernardo Houssay refletia nas décadas de 1930 e 1940 sobre a importância de uma cooperação científica sul-americana, laços de amizade com as instituições “da América Espanhola e do Brasil” (1936b),

\footnotetext{
${ }^{13}$ Em termos linguísticos, uma sequela para o espanhol (e para outras línguas "periféricas" da ciência), como efeito da proliferação de artigos em inglês, reside nas limitações da inovação lexical, do vocabulário especializado e até mesmo de gêneros discursivos específicos (ALCINA CAUDET, 2001, ARNOUX, 2015).
} 


\section{$\mathrm{El} \square \mathrm{dA}$}

compreendia que os avanços dos países fraternos repercutiam positivamente no progresso e reputação de uma ciência regional; nestas páginas prevalece uma visão dependentista de endosso e da difusão provenientes dos principais centros científicos.

Ao longo do trabalho observou-se o mecanismo argumentativa da polêmica por meio do uso de estratégias lógicas (raciocínios, dados quantitativos) e emocionais (depreciação da condição emocional do interlocutor), bem como algumas premissas (lugar da quantidade, valor do útil) e técnicas argumentativas (par filosófico e antitético); e foi dada atenção a certas características da dimensão enunciativa (uso de expressões modalizadoras, articulação de enunciados concessivos e adversativos) em função da análise do confronto. É possível ver como as respostas de Cabib, voz que opera como eixo discursivo, pois é o único que responde às intervenções opostas a seu ponto de vista, adaptam-se e reproduzem os recursos e a lógica das considerações anteriormente recebidas. Assim, o grau de confronto recebido (do "ataque cordial" - ou, ainda mais "elogioso" à desclassificação explícita) reflete-se na formulação de suas respostas. Da mesma forma, procura refutar e contra-argumentar com dados quantitativos concreto às perguntas feitas a partir dessa lógica. Atento às interpretações errôneas de seus enunciados, Cabib expõe a "confusão" ou os mal-entendidos de seus opositores no desenvolvimento de uma polêmica na qual, sem deixar de primar pelo dissenso, manifestam-se a leitura atenta e intercâmbio lógico de ideias. Para além da reflexão argumentativa, entendo que esta controvérsia nos desafia, pesquisadores e cientistas atualmente ativos, particularmente aqueles que produzimos nosso trabalho em diferentes idiomas ou em espaços distantes das grandes potências científicas. Talvez permita que comecemos a nos perguntar sobre a o caráter determinante dos critérios que vinculam a qualidade, o prestígio, o interesse e os impactos das pesquisas realizadas em função da área em que são publicadas ou na língua em que são produzidas.

\section{Fontes}

BARÓN, M. ¿Deben publicarse revistas científicas en la Argentina? Ciencia e Investigación, Buenos Aires, t. 17, n. 10, p. 443-445, oct. 1961. 
$\mathrm{EI} \square \AA \mathrm{A}$

Revista Eletrônica de Estudos Integrados em Discurso e Argumentação, Ilhéus, n. 17, jul./dez. 2018

BURKART, A. ¿Deben publicarse revistas científicas en la Argentina? Ciencia e Investigación, Buenos Aires, t. 17, n. 3, p. 52-53, mar. 1961.

CABIB, E. ¿Deben publicarse revistas científicas en la Argentina? Ciencia e Investigación, Buenos Aires, t. 16, n. 7, p. 247-249, ago. 1960.

CABIB, E. ¿Deben publicarse revistas científicas en la Argentina? Ciencia e Investigación, Buenos Aires, t. 17, n. 3, p. 53, mar. 1961 a.

CABIB, E. ¿Deben publicarse revistas científicas en la Argentina? Ciencia e Investigación, Buenos Aires, t. 17, n. 10, p. 445, oct. 1961b.

CARDINI, C. ¿Deben publicarse revistas científicas en la Argentina? Ciencia e Investigación, Buenos Aires, t. 17, n. 3, p. 53-54, mar. 1961.

CATTÁNEO, P. ¿Deben publicarse revistas científicas en la Argentina? Ciencia e Investigación, Buenos Aires, t. 17, n. 3, p. 50-52, mar. 1961.

MEYER, T. ¿Deben publicarse revistas científicas en la Argentina? Ciencia e Investigación, Buenos Aires, t. t. 17, n. 3, p. 49-50, mar. 1961.

CIENCIA E INVESTIGACIÓN, Buenos Aires, t. 17, n. 10, p. 538, oct. 1961.

\section{Referências}

AMOSSY, Ruth. Argumentação e Análise do Discurso: perspectivas teóricas e recortes disciplinares. Tradução: Eduardo Lopes Piris e Moisés Olímpio Ferreira. EID\&A Revista Eletrônica de Estudos Integrados em Discurso e Argumentação, llhéus, n.1, p. 129-144, 2011.

AMOSSY, Ruth. Por una retórica del dissensus: las funciones de la polémica. In: MONTERO, Ana Soledad. (comp.). El análisis del discurso polémico. Prometeo: Buenos Aires, 2016. p. 25-38.

ANGENOT, Marc. Diálogos de sordos: tratado de retórica antilógica. In: MONTERO, Ana Soledad. (comp.). El análisis del discurso polémico. Prometeo: Buenos Aires, 2016. p. 39-54.

ARNOUX, Elvira Narjava de. Minorización lingüística y diversidad: en torno al español y al portugués como lenguas científicas. Anais do Seminário Ibero-americano de Diversidade Linguística. Brasilia: Iphan, 2015. p. 290-306.

ALCINA CAUDET, María Amparo. El español como lengua de la ciencia y de la medicina. Panace@, Córdoba, v. 2, n. 4, jun. 2001. Disponível em: http://www.medtrad.org/panacea/PanaceaAnteriores.htm. Acesso em: 5 fev.2018.

BUCHBINDER, Pablo. Historia de las universidades argentinas. Buenos Aires: Sudamericana, 2005. 


\section{$\mathrm{EI} \square \mathrm{\alpha A}$}

Revista Eletrônica de Estudos Integrados em Discurso e Argumentação, Ilhéus, n. 17, jul./dez. 2018.

GAVIOLA, Enrique. Carta del Presidente de la Asociación Física Argentina al Presidente de la República. Ciencia e Investigación, Buenos Aires, t. 3, n. 4, p. 116-118, mar. 1948

HAMEL, Rainer Enrique. El campo de las ciencias y la educación superior entre el monopolio del inglés y el plurilingüismo: elementos para una política del lenguaje en América Latina. Trabalhos em Linguística Aplicada, Campinas, v. 52 n. 2, jul. 2013. Disponível em: https://periodicos.sbu.unicamp.br/ojs/index.php/tla/issue/archive. Acesso em: 20 fev.2018

HOUSSAY, Bernardo. Santiago Ramón y Cajal. In: BARRIOS MEDINA, Ariel. (comp.). Escritos y discursos del Dr. Bernardo Houssay. Buenos Aires: Eudeba, 1989 [1934]. p. 428-432.

. Discurso en la comida de los delegados al Tercer Centenario de la Universidad de Harvard. In: BARRIOS MEDINA, Ariel. (Comp.). Escritos y discursos del Dr. Bernardo Houssay. Buenos Aires: Eudeba, 1989 [1936a]. p. 574-575.

. Discurso al asumir la presidencia de la Academia Nacional de Medicina. In: BARRIOS MEDINA, Ariel. (Comp.). Escritos y discursos del Dr. Bernardo Houssay. Buenos Aires: Eudeba, 1989 [1936b]. p. 569-573.

. Obstáculos y estímulo a la investigación científica. In: BARRIOS MEDINA, Ariel. (comp.). Escritos y discursos del Dr. Bernardo Houssay. Buenos Aires: Eudeba, 1989 [1958]. p. 348-358.

. El presente y el porvenir de la fisiología. In: BARRIOS MEDINA, Ariel. (comp.). Escritos y discursos del Dr. Bernardo Houssay. Buenos Aires: Eudeba, 1989 [1959]. p. 212-220.

HURTADO, Diego; BUSALA, Analía. De la movilización industrial a la Argentina científica: La organización de la ciencia durante el peronismo (1946-1955). Revista Da SBHC, Rio de Janeiro, v. 4, n. 1, 2006. Disponível em: http://www.sbhc.org.br/revistahistoria/public. Acceso em: 20 fev. 2018.

; _. La divulgación como estrategia de la comunidad científica argentina: la revista Ciencia e Investigación (1945-48). Redes, Quilmes, a. 9, n. 18, 2001. Disponível em: http://iec.unq.edu.ar/index.php/publicaciones/revista-redes. Acceso em: 20 fev. 2018.

KERBRAT-ORECCHIONI, Catherine. La polémique et ses définitions. In: GELAS, Nadine; . (ed.). Le discours polémique. Lyon: PUL, 1980. p. 3-40.

. Sarkozy polemista: la "descalificación cortés" del adversario. In: MONTERO, Ana Soledad. (comp.). El análisis del discurso polémico. Prometeo: Buenos Aires, 2016. p. 97-122.

MAINGUENEAU, Dominique; CHARAUDEAU, Patrick. (ed.). Dictionnaire d'analyse du discours. París: Seuil, 2002. [Tradução em português: MAINGUENEAU, Dominique; 
$\mathrm{El} \square \mathrm{dA}$

Revista Eletrônica de Estudos Integrados em Discurso e Argumentação, Ilhéus, n. 17, jul./dez. 2018

CHARAUDEAU, Patrick (org.). Dicionario de análise do discurso. Contexto: São Paulo, 2006.]

MONTERO, Ana Soledad. La polémica y lo polémico. Palabras preliminares. In: (comp.). El análisis del discurso polémico. Prometeo: Buenos Aires, 2016. p. 9-22.

MONTES DE OCA, Leopoldo. Discurso del Vice-Presidente de la Nueva Escuela de Medicina. In: CANTÓN, Eliseo. La facultad de medicina y sus escuelas. Buenos Aires: Casa Editora Coni. 1921 [1852]. p. 263-264.

NAVARRO, Fernando A.. El inglés, idioma internacional de la medicina. Causas y consecuencias de un fenómeno actual. Panace@, Córdoba, v. 2, n. 3, mar. 2001. Disponível em: http://www.medtrad.org/panacea/PanaceaAnteriores.htm. Acesso em: 5 fev.2018.

PERELMAN, Chaïm; OLBRECHTS-TYTECA, Lucie. Tratado de la argumentación. La nueva retórica. Traducción española: Julia Sevilla Muñoz. Madrid: Gredos, 1989. [Tradução em português: PERELMAN, Chaïm; OLBRECHTS-TYTECA, Lucie. Tradução: Maria Ermantina Galvão. Tratado da argumentação: a nova retórica. São Paulo: Martins Fontes, 1999].

PLANTIN, Christian. De polemistas a polemizadores. In: MONTERO, A. (Comp.). EI análisis del discurso polémico. Prometeo: Buenos Aires, 2016. p. 67-82.

RAMOS MEJÍA, José María. Estudios Clínicos de enfermedades nerviosas y mentales. Buenos Aires: Félix Lajouane, 1893.

YANGUAS, Josefina. Eduardo Braun Menéndez y las publicaciones científicas. In: PEÑA, Ignacio (ed.). Eduardo Braun Menéndez. Ciencia y conciencia. Una vida inspiradora. Buenos Aires: Ministerio de Ciencia, Tecnología e Innovación Productiva, 2015. p. 94-97.

\section{Tradução}

Alexandre Marques Silva

Doutor em Filologia e Língua Portuguesa pela Universidade de São Paulo

\section{Forma de citação sugerida}

von STECHER, Pablo. Discurso e polêmica sobre a publicação de revistas científicas na Argentina (1960). Tradução: Alexandre Marques Silva. EID\&A - Revista Eletrônica de Estudos Integrados em Discurso e Argumentação, Ilhéus, n. 17, p. 103-121, jul./dez.2018. DOI dx.doi.org/10.17648/eidea-17-1899. 